\title{
The Sr-90 Fallout and the Air Motion
}

\author{
by \\ Y. Miyake, K. Saruhashi and Y. Katsuragi \\ Meteorological Research Institute, Tokyo
}

(Received January 17, 1959)

\begin{abstract}
The cumulative amount of $\mathrm{Sr}-90$ in Tokyo through the middle of 1958 reached $11.3 \mathrm{mc} / \mathrm{km}^{2}$. The fall rate of $\mathrm{Sr}-90$ has the positive correlation of +0.69 with the rainfall amount but it has no spring maximum as suggested by MACHTA et al. The estimated amount of fallout in the future will be about $50 \mathrm{mc} / \mathrm{km}^{2}$ even if nuclear tests stop now. The average age of fallout which is calculated from the ratio of Sr-89 and Sr-90 was from 200 to 300 days. The difference between the atmospheric ozone and the $\mathrm{Sr}-90$ in the stratosphere is discussed. It is concluded that the radioactive deposit on the earth is affected by locations and seasons of injection of $\mathrm{Sr}-90$ into the stratosphere as well as the turbulent motion on a larger scale.
\end{abstract}

\section{Results of observation of Sr-90 fallout in Japan}

Chemical analysis of the monthly Sr-90 fallout in Japan got under way a few years ago. The cumulative amount of Sr-90 in Japan through July, 1957 was reported already in the previous article (1957). This paper deals with the Sr-90 fallout in Japan in relation to the meteorological factors.

Fig. 1 shows the cumulative Sr-90 deposition in Tokyo during the period from the beginning of 1956 through the middle of 1958. In Fig. 2 are shown the changes of monthly values of Sr-90 fallout $\left(\mathrm{mc} / \mathrm{km}^{2}\right)$, the amount of precipitation $(\mathrm{mm})$ in Tokyo and the total amount of ozone $(\mathrm{cm})$ observed at Tateno. The total amount of ozone was determined by the use of Dobson's spectrophotometer at the Aerological Observatory located about $100 \mathrm{~km}$ northeast of Tokyo. As shown in Fig. 2, there is a remarkable positive correlation between $\mathrm{Sr}-90$ fallout and the amount of precipitation.

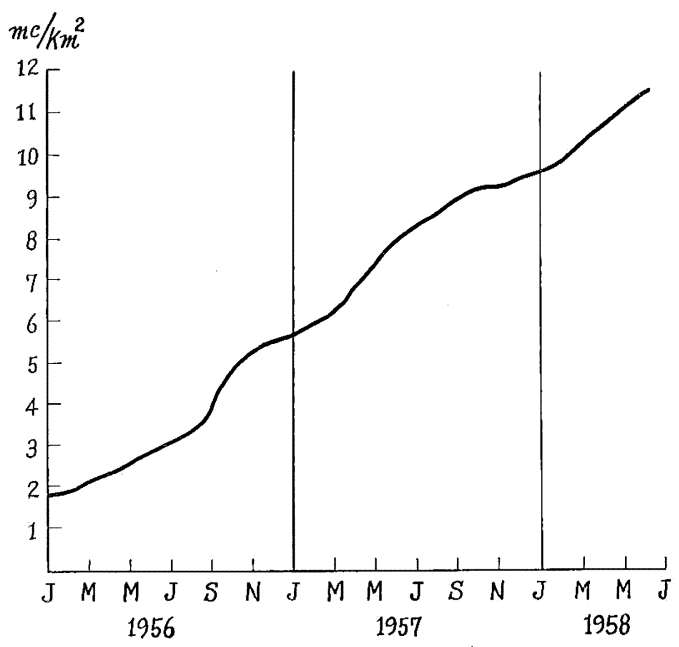

Fig. 1. Cumulative ground deposition of $\mathrm{Sr}-90$ in Tokyo $\left(\mathrm{mc} / \mathrm{km}^{2}\right)$. 
Total Ozone Amount at Tateno

(Thickress of Ozone, STP. cm)
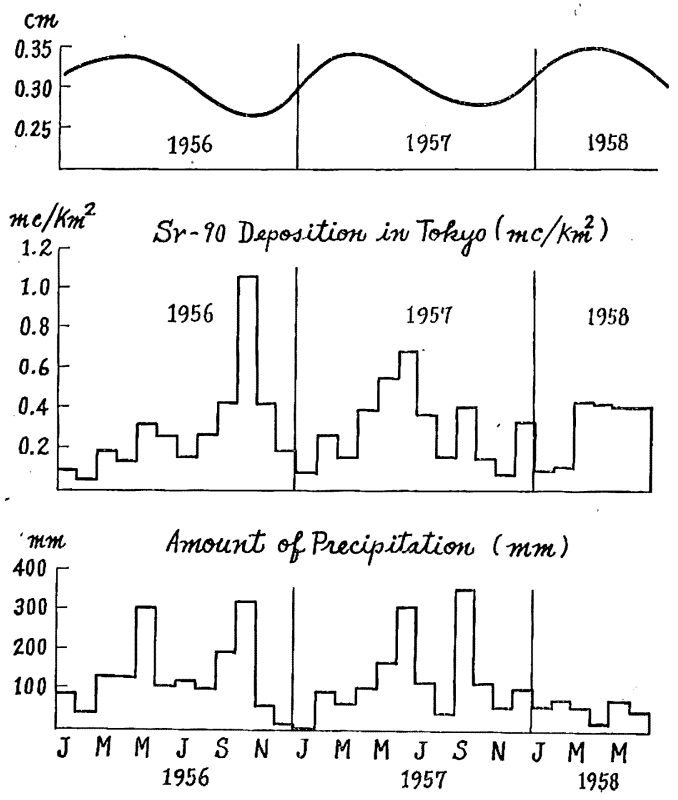

Fig. 2. Total ozone amount, Sr-90 deposition and amount of precipitation.

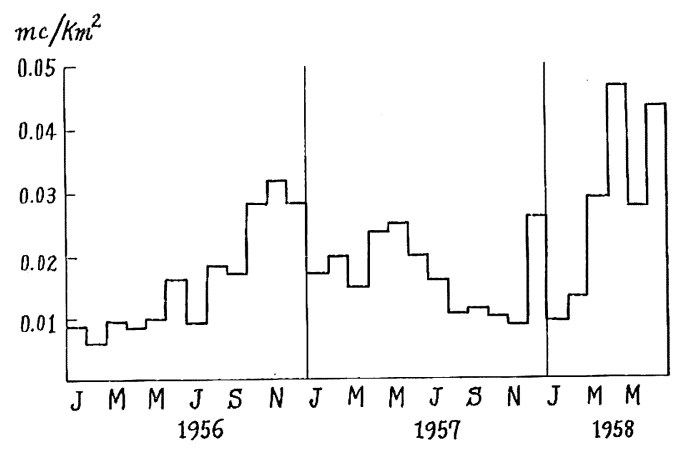

Fig. 3. The amount of $\mathrm{Sr}-90$ in rain bearing layer.

The correlation coefficient between $\mathrm{Sr}-90$ fallout and the precipitation amount was +0.69. On the other hand, there is no spring maximum in Sr-90 deposition nor the positive correlation with the ozone amount as suggested by Machta (1957) and Stewart et al (1957) respectively in USA and UK.

The monthly strontium fallout $(S)$ consists of dry fallout $(D)$ and rainout $(R)$ which can be expressed as follows

$$
R=S-D=\sum C\left(1-e^{-\beta P}+k P\right)^{*},
$$

where, $C$ is the amount of Sr-90 in the rain-bearing air column above the ground; $P$, the amount of precipitation of each rainfall in a month; $\beta$, a constant relating to the rate of capture of dust particles by rain drops; $k$ is also a constant. Roughly speaking, the rate of strontium-90 rainout depends on both the frequency and the amount of precipitation.

Assuming that $\beta$ is $2^{*}$ and $k$ is 0.07 , averaged value of $C$ can be obtained using observed values of $P, R$ and $D$ in each month. The results of calculation are shown in Fig. 3.

Assuming that the height of the top of rain making layer is $1 / 2.5$ of that of the tropopause, the amount of Sr-90 in the troposphere in 1958 would be about $0.1 \mathrm{mc} / \mathrm{km}^{2}$ which is equivalent to $1.5 \times 10^{-20}$ curie $/ \mathrm{cm}^{3}$ in the air at NTP. As will be given later, the stratospheric inventory of Sr-90 through the middle of 1958 is estimated to be about $50 \mathrm{mc} / \mathrm{km}^{2}$ which equals $3 \times 10^{-17}$ curie $/ \mathrm{cm}^{3}$ (NTP) assuming that the amount of the air in the stratosphere is $20 \%$ of the total. Thus, the ratio of the stratospheric Sr-90 concentrations will be of the order of 1000 which is in agreement with the observations in the past. The air concentration of $\mathrm{Sr}-90$ in 1954 and 1955 was about $0.1-0.3$

* Miyake, Y. and Sugiura, Y. (1950). 
$\times 10^{-20}$ curie $/ \mathrm{cm}^{3}$ in Washington DC (MARTELL, 1957) while the stratospheric Sr-90 concentration was about $2 \times 10^{-18}$ curie $/ \mathrm{cm}^{3}$ on an average (LibBY, 1958).

In Fig. 4 the averaged age of the fallout which was calculated by the determination of Sr-89 and Sr-90 are given. The result shows that the averaged age increased from about 200 days to 300 days during the period of two years from the middle of 1956 to that of 1958. This suggests that the larger part of the fallout consists of the older fission products stored in the stratosphere. Unfortunately, however, tests have been made so many times successively in the past, that the rate of fallout from the stratosphere can not be calculated from these data.

Up to the end of 1957 the barometric oscillations which were caused by the explosions of the multi-megaton TNT class were found twenty one times in Japan. In the year of 1958, the oscillations were observed as many as twenty nine times, of which thirteen were due to the Pacific tests and the rest were attributed to Russian tests. If we assume the fission yield of such nuclear explosions is about the same during the past, we have to conclude that the future accumulation of

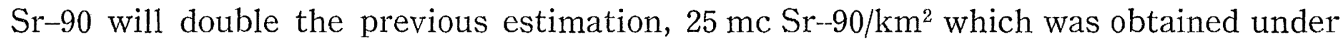
the assumption that tests had been stopped in the middle of 1957 . The newly estimated amount of Sr-90 accumulation would be about $50 \mathrm{mc} / \mathrm{km}^{2}$ when tests were stopped at the end of 1958. Assuming that the averaged energy of explosions which were detected by the barometric oscillations is five megatons TNT and that a half of the energy is produced by the fission process, the average amount of Sr-90 deposition would be about $18 \mathrm{mc} / \mathrm{km}^{2}$ after ten years. When the accumulation of $\mathrm{Sr}-90$ in the temperate zone of the northern hemisphere is three times of the average, it would be $54 \mathrm{mc} / \mathrm{km}^{2}$ which is fairly close to the above estimation.

\section{Fallout and air motion}

As mentioned above, according to the results of the chemical analysis of the monthly Sr-90 deposition in Tokyo there was no spring maximum nor positive correlation with the total ozone amount.

The radioactive fallout and the air motion will be discussed here especially in connection with the atmospheric ozone. MiYake and Saruhashi (1951) showed that the ozone in the upper atmosphere is produced by the photochemical reaction and shows its maximum rate of production in summer when the intensity of the solar radiation is strongest and the minimum in late December. As to the meridional distribution, the production rate of ozone is the largest in the tropical area, smaller in the temperate and the smallest in the polar regions. However, in the upper atmosphere, there is a pole-ward component of air flow as well as the horizontal diffusion which brings about the characteristic meridional distribution and the seasonal variation of the ozone amount. In other words, the spring maximum and 
the autumn minimum of ozone and the maximum in the higher latitudes at about $65^{\circ}$ are not simply due to the dynamical motion of the air at higher altitudes, but they should be regarded as resulting from superposition of the photochemical reaction and the general circulation of the upper air.

The feature common to the radioactive, air-borne dust and the atmospheric ozone is that most of them exists in the stratosphere. However, unlike the photochemical formation of ozone, the radioactive dust is injected into the stratosphere from time to time, from a small number of point sources. Two of them are located in the tropical Pacific, others are in the Central Asia, the south-west part of Siberia and the Arctic Ocean.

The larger tests in the Pacific used to be done during the period from spring to early summer, while those on the middle and higher latitudes were done during the season from fall to late winter.

The radioactive dust which is injected into the stratosphere moves around the earth along the zonal wind, gradually spreading out in the meridional direction by the horizontal diffusion and the pole-ward flow of the air. It is believed that the angle of the horizontal diffusion in the stratosphere is small and the mean flow rate of pole-ward transport is of the order of less than a few meters per second. Therefore, it will take much time to distribute radioactive dust evenly in the stratosphere. In addition, since tests were done many times at a certain location successively during a few months' period, dust clouds were concentrated for a considerably long time in the zone in which a test site was situated. Especially in the temperate and polar regions in the northern hemisphere, the accumulation and the descending motion are strong in fall and winter when most of the tests in USSR were done. This may account for the fact that the deposition of radioactive dust was concentrated in the region between $40^{\circ}$ and $50^{\circ} \mathrm{N}$.

On the other hand, in the tropical area, a part of the dust clouds which are injected in the northern side of the equator in summer is transported into the southern hemisphere due to the southward component of the upper wind, therefore, the zonal accumulation of radioactivity might be much less when the test is done in summer in the tropical area. This may be one of the reasons why the deposition of Sr-90 originating from the Pacific area is sometimes not only delayed but diffused.

As to the causes of sinking of the air-borne dust from the stratosphere into the troposphere, there is a descending motion on the middle and higher latitudes in winter time due to the general circulation of the air as MAcHTA (1957) pointed out. However, we should also consider another cause of sinking of the air, i.e. the local turbulent motions. As is well known, the ozone amount usually shows the maximum in the rear side of a cyclone and the minimum in the vicinity of a centre of an anticyclone. MiYake and Kawamura (1954) showed that the ozone amount becomes greater when the observation point is situated near and in front of the trough at the level of about $500 \mathrm{mb}$. These are considered as the sinking and ascending of the upper air by the turbulent motion. By such a motion of the air, the dust in the stratosphere comes down into the troposphere. It is also known that the ozone content near the ground shows the daily maximum at noon which is attributed to the increased rate of exchange of the air between the lower and the higher altitudes. These facts suggest that a part of the radioactive dust in the strato- 
sphere is also able to penetrate the tropopause owing to the turbulent motion of the air on a larger scale.

In conclusion, the radioactive deposit on the earth seems to be affected considerably by the location and the season of injection of debris into the stratosphere as well as the turbulent motion, though we should not underestimate the effect of the general circulation of the air.

\title{
References
}

Liвву, F.W., 1958: Radioactive fallout, for delivery before the Swiss Academy of Medical Sciences, Lausanne, Switzerland, March 27, 1958.

MACHTA, L., 1957: Discussion of meteorological factors and fallout distribution. Presented at Symposium on Low Level Irradiation, Indianapolis, Indiana, USA, Dec. 30, 1957.

Machт, L., 1958: Meteorological interpretation of Sr-90 fallout. Presented at Public Meeting, May 1, 1958, Washington D.C.

Marteld, E.A., 1957: Strontium-90 concentration data for biological materials, soils, waters and air filters. Project Sunshine Bulletin, No. 11, AECD-3762.

Mtyake, Y. and Kawamura, K.: Studies on atomospheric ozone at Tokyo. Scientific Proc. of International Association of Meteorology, Tenth General Assembly, Rome, Sept. 1954, pp. 172-176.

Miyak.e, Y. and Sugrura, Y., 1950 : The mechanism of dissolution of atmospheric chloride into rain water. Papers in Meteorology and Geophysics, (Tokyo), 1, 222-226.

Mryake, Y. and Saruhashi, Miss K., 1951: On the annual and meridional variation of the atmospheric ozone. Papers in Meteorology and Geophysics, 2, 150.

Miyak., Y., Sugiura, Y., Saruhashi, Miss K. and Kanazawa, Mrs. T., 1957: The estimation of the amount of Sr-90 deposition and the external infinite gamma dose in Japan due to man-made radioactivity. UN Scientific Committee on the Effects of Atomic Radiation, Document A/AC, 82/G/R, No. 172 .

Stewart, N.G., Osmond, R.G.D., Crooks, R.W. and Fisher, Miss E.M., 1957: The world-wide deposition of long-lived fission products from nuclear test explosions. A.E.R.E. MP/R 2354 Oct. 1957.

\section{Sr-90 の落下と大気の運動}

\author{
三宅泰雄，猿橋勝子，葛城幸焳
}

\footnotetext{
1958 年なかばまでの, 東京に扮ける Sr-90 の蓄穦量は $11.3 \mathrm{mc} / \mathrm{km}^{2}$ そ達した。 $\mathrm{Sr}-90$ の落下量は, 降雨量と +0.69 の正の相関関係をもつているが，MACHTA らが示したような春先の極大はない。

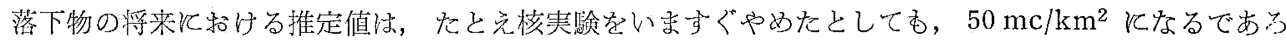

う。落下物の平均年令は，Sr-89 と Sr-90 の比から 200 日から 300 日であることが計算された。

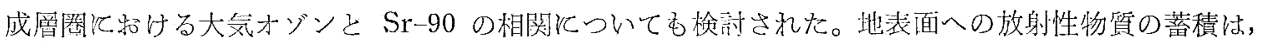

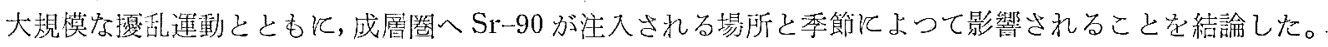

